\title{
Few Adverse Reactions to Metal on Metal Articulation in Total Hip Arthroplasty in a Review Study on 358 Consecutive Cases with 1 to 5 Years Follow-Up
}

\author{
Jens Stürup ${ }^{*}$, , Line B. Dahl ${ }^{1}$, Karl-Erik Jensen ${ }^{2}$, Anne-Birgitte Larsen ${ }^{3}$ and Peter Gebuhr ${ }^{3}$ \\ ${ }^{I}$ Orthopaedic Department U, 2162, Rigshospitalet, University of Copenhagen, Denmark \\ ${ }^{2}$ Department of Radiology, Rigshospitalet, University of Copenhagen, Denmark \\ ${ }^{3}$ Orthopaedic Department, Hvidovre Hospital, University of Copenhagen, Denmark
}

\begin{abstract}
The aim of the present study was to determine the frequency of adverse reaction to metal on metal total hip arthroplasty using a M2a-38 articulation and a Magnum articulation, (Biomet Warsaw, Indiana).

All patients who had received a Metal on Metal bearing prosthesis, in two centres in Copenhagen, were asked to complete a questionnaire about groin pain. Patients with self-reported groin pain, 68/314, underwent a physical examination and had $\mathrm{Co}$ and $\mathrm{Cr}$ ion levels measured in full blood samples. Fifty patients also had a CT scan performed.

The present study found one patient with bilateral arthroplasty, who had an adverse reaction on one side. In addition the study showed that females had higher values of $\mathrm{Co}$ and $\mathrm{Cr}$, and that younger patient reported groin pain more often.

The conclusion of this study is that the number of adverse reactions is low, despite the time of observation being relatively short, no high frequency of adverse reactions to this prosthesis is expected.
\end{abstract}

Keywords: Metal on metal, hip, ALVAL, Pseudotumor.

\section{INTRODUCTION}

Metal on Metal bearing (MoM) in Total Hip Arthroplasty (THA) was introduced as it enabled the use of large femoral heads, which added to the stability of the hip [1]. In addition the hard on hard bearing was more wear resistant than standard metal on polyethylene bearing. However, reports of development of pseudotumors as a possible result of a reaction to Cobolt $(\mathrm{Co})$ and Cromium $(\mathrm{Cr})$ wear products, has emerged giving rise to some concern for the ongoing use of this type of articulation. Medicines \& Healthcare products Regulatory Agency in the UK (MHRA) issued a Medical Device Alert (MDA) (MDA/2010/033), which was followed by an interpretation by The British Orthopaedic Association, giving advice on how to follow patients, with a MoM articulation. Following this advice the Danish orthopaedic Society made a review of the current literature, and gave advice on how patients should be followed [2].

This review associated with MoM related pseudotumor, with a poorly defined exclusion diagnosis, revealed that the tissue reaction often with histological characteristic appearance named "aseptic lymphocyte dominated vasculitis associated lesion" (ALVAL) [3]. In the Danish review clinical relevant hip pain, demanding follow up action, was defined as groin pain for more than 1 month.

\footnotetext{
*Address correspondence to this author at the Orthopaedic Department U, 2162, Rigshospitalet, University of Copenhagen, Denmark, Blegdamsvej 9, 2100 Copenhagen $\varnothing$, Denmark; Tel: +4521483713;

E-mail: Styrup16@hotmail.com
}

The characteristics of the lesions can be graded by an ALVAL score as described by Campbell [4]. Pseudotumor is, however, not specific for metal on metal articulations, but is a well-known phenomenon among revision surgeons occurring in other articulations as well [5,6]. Most literature on the subject is on the resurfacing arthroplasties, where the incidence of pseudotumor is reported to be approximately $1 \%$ [7]. Edge loading in steep cups has been associated with excessive wear and pseudotumor [8]. The Danish review believed that the substantial problems reported, in some cases, might be associated with design features of certain products. The aim of the present study was to review the patients, who had received MoM articulations with 2 different MoM bearings, M2a-38 (Biomet) and Magnum/Recap (Biomet)' to see if some patients with destructive tissue reactions had been overlooked and determine the frequency of reactions.

\section{PATIENTS AND METHODS}

A cross sectional study was performed including all patients operated on with a THA with MoM articulation, in Rigshospitalet and Hvidovre Hospitals, during the period 2004 to 2009. Three hundred and fifty-eight cases were identified through the Danish national hip register. Two patients ( 2 cases) could not be identified, due to insufficient social security numbers in the database, leaving 356 cases (324 patients) for review (191 male and 165 female cases). Median age at the time of operation was 59 years (range 18 95 years). Eighty-five hips had received a M2a-38 cup with fixed head size of $38 \mathrm{~mm}$, and 271 hips a magnum articulation with variable head size, $6 \mathrm{~mm}$ less than the cup 
diameter. Sixteen patients (16 cases) had died and 17 hips were revised. Seven patients ( 7 cases) were lost to follow-up (3 patients had emigrated, 1 patient suffered from severe dementia, and 3 patients did not respond to the questionnaire despite several attempts to retrieve the information). The patients lost to follow up had their hospital records reviewed.

The remaining 316 cases, (289 patients) (173 male and 143 female cases), median age 59 years $(18-87)$ returned the questionnaire. The patients were specifically asked about groin pain during the last month. In addition the patients filled in the questionnaire part of the Harris Hip score and a 4 step satisfaction score.

Five patients, who had responded to the questionnaire claiming groin pain, refused clinical examination.

The remaining patients, who returned the questionnaire complaining from groin pain, underwent a clinical followup, with Harris Hip score and radiographs, consisting of a full frontal pelvis, an AP and a lateral projection.

The radiographs were evaluated by the same authors for radiographic signs of loosening and cup inclination. All these patients had blood samples obtained for measurement of $\mathrm{Co}$ and $\mathrm{Cr}$ ion content in full blood [9]. Values below 7 ppm were considered to be normal (MDA/2010/033). The Samples were examined by "Inductively coupled plasma Sector Field Magnet Spectrometry" (ICP-SFMS) by ALS Scandinavia, Sweden. In addition sedimentation rate, CRP and leukocyte count were recorded, in order to reveal infection. Some patients, with alternative obvious reasons for their complaints, had no further investigations performed (12 patients, 13 cases). Of these 12 patients, 7 did not have any pain when questioned during the consultation, 3 had CT scan performed following this study without registration of any pseudotumor, one had lower back pain and one had infection with fistulation and was consequently re-operated. The remaining 50 cases had a CT scan performed, in order to identify possible pseudotumors. The CT scan was performed with an ordinary clinical 64-MDCT (multi-detector computed tomography) scanner (Aquilion TSX-101A/HA, Toshiba Medical Systems Co., Tokyo, Japan), with the following protocol : collimation $(0.625 \mathrm{~mm} \times 64)$, helical pitch (0.983), gantry rotation $(0.5 \mathrm{sec})$, scan length (220 $\mathrm{mm})$, tube voltage $(140 \mathrm{kV})$ and varying tube current (depending on patient size). Soft tissue filter (Y-sharp YA and smooth A) and artefact minimization software (16 bit data processed on an extended scale) was used. The radiation dose of this pelvic CT scan ranged between 10 and $16 \mathrm{mSv}$ depending on the body mass of the patient. Due to the excellent signal-to-noise ratio, the periprostetic soft tissues could be evaluated for pathology.

The term "pseudotumor" was originally used, to describe a solid granulomatous mass related to a collection of artificial debris related to prosthetic wear.

In some patients there is no granulomatous mass, but an effusion with or without a capsule. In others there is no mass and only minimal fluid collection. Thus, the term "pseudotumor" detected on CT-images, covers a wide range of lesions from simple minor effusions, to large solid masses and the final diagnosis is always based on exclusion.

\section{STATISTICS}

The primary outcome was defined to be presence of pseudotumor (ALVAL). Two secondary outcomes were increased values for $\mathrm{Cr}$ and $\mathrm{Co}$ ion levels in whole blood samples, and reported groin pain during the last month.

Data on patients with self reported groin pain $(\mathrm{N}=68)$ was compared to data for patients without groin pain ( $\mathrm{N}=246$ ). Data on patients with elevated $\mathrm{Co}$ and $\mathrm{Cr}$ ion levels $(\mathrm{N}=15)$ were compared to data on patients with normal ion levels $(\mathrm{N}=35)$.

Chi square analysis was used to compare the nonparametric data, distributed on a nominal scale. Independent t-test was used to compare mean values for numeric data. One sample t-test was used to report $95 \%$ confident interval on the mean.

All statistical analyses were performed using SPSS version 20 (SPSS Inc., Chicago, Illinois). The level of significance was set to $\mathrm{P} \leq 0,05$.

\section{ETHICAL CONSIDERATIONS}

All patients gave informed consent to participation in this investigation. Data were kept anonymous and treated confidentially. The investigation was conducted in accordance with the Helsinki declaration and reported to the local ethical committee, 10.08.11 protocol no. H-2-2011FSP26 and approved by The Danish Data Protection Agency.

\section{RESULTS}

Median follow-up on the 316 cases, who responded to the questionnaire, was 3.5 years range $(1.1-6.4)$ years. None of the deceased patients $(n=18)$ had their hips revised. Records from the 17 revised patients did not reveal any description of pseudo tumor like lesions in any of the cases (Table 1).

Table 1. Causes of Revisions Performed Prior to this Study

\begin{tabular}{|c|c|}
\hline Cause of Revision & Number (n=17) \\
\hline \hline Femoral fracture & 5 \\
\hline Unequal leg length & 3 \\
\hline Aseptic loosening & 3 \\
\hline Infection & 2 \\
\hline Dislocation & 1 \\
\hline Psoas tendinitis & 1 \\
\hline Squeaking & 1 \\
\hline Component failure (disengaged cone) & 1 \\
\hline
\end{tabular}

The $50 \mathrm{CT}$-scans performed in the symptomatic cases, revealed 2 patients with a pseudo tumor like lesions. One female patient age 68 years, with a Magnum articulation (head size 46), only had weak symptoms and surgical intervention was postponed. On the original CT scan the process was situated anterior to the hip joint next to iliopsoas and measured $6 \times 3 \times 3 \mathrm{~cm}$. The patient had normal values 
for sedimentation rate, C-reactive protein and leukocyte count. $\mathrm{Cr}$ and $\mathrm{Co}$ values were 4.9 and $5.2 \mathrm{microgram} / \mathrm{litre}$. Cup inclination was $36^{\circ}$. The symptoms disappeared and 6 month later an ultrasonic examination, showed the cystic tumor had diminished, and now measured only $3 \times 2 \times 1 \mathrm{~cm}$ and was interpreted as an irritated bursa iliopectineus (Fig. 1).

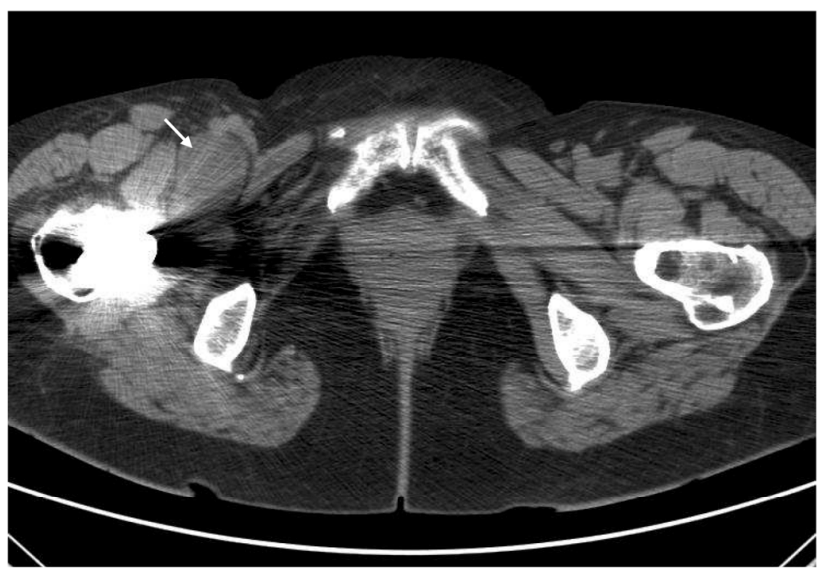

Fig. (1). Bursa iliopectineus in metal on metal THA patient.

The other patient with a cystic tumor was a 35 years old female, with bilateral Magnum articulation and clinical and radiographic signs of loosening of one cup with osteolysis. Blood samples revealed normal values for sedimentation rate, C-reactive protein and leukocyte count. $\mathrm{Cr}$ and $\mathrm{Co}$ values were elevated (19.1 and 31.3) microgram/litre. Cup inclination was $40^{\circ}$ and $48^{\circ}$ respectively. Both cups were revised. In the case with the loose cup, milky white fluid was extracted from the joint, and a soft tissue component was examined, revealing grade 8 ALVAL reactions. The opposite cup was revised too, in accordance to the patients wish. Only a few mls. of clear fluids were found in the joint and tissue samples did not reveal any signs of ALVAL at all.

Analyses of the two groups, with and without selfreported groin pain, showed that the patients with groin pain were significantly younger. We could not find any relation to time to follow up, femoral head size, sex or type of cup used (Table 2).

50 patients had groin pain on examination. 15 of these patients had elevated Co- and $\mathrm{Cr}$ ion levels. No patients had elevation of one ion level without elevation of the other ion level too.

Comparing cases, with and without elevated $\mathrm{Co}$ or $\mathrm{Cr}$ levels, revealed significant more females with elevated ion levels, compared to male. There were no difference between the groups concerning age, follow up time, head size, type of cup, satisfaction, Harris hip score and cup inclination (Table 3).

\section{DISCUSSION}

Pseudotumor is a vaguely described reaction to an implant, sometimes with histological characteristics described as ALVAL [3]. This vague description of the phenomenon makes comparison of results difficult.

Patients with self-reported groin pain were younger than patients without. This corresponds with the findings from Bartelt et al. [10]. Nasser et al. [11] could however not find a correlation between groin pain and age with Resurfacing Total Hip Replacement (RTHA). There seems to be confounding data on age as a risk factor for groin pain. One explanation for such a correlation could be higher level of activity and expectation in the younger age groups.

Patients with elevated $\mathrm{Cr}$ and $\mathrm{Co}$ ion levels did not have a significant higher cup inclination compared to patients with normal ion levels. R. De Haan et al. 2008 [12] found in RTHA, steep cups $\left(>55^{0}\right)$ associated with elevated ion levels. DJ Langton et al. 2008 [13] found a correlation between elevated ion levels and steep cups with small heads $(<51 \mathrm{~mm})$, but no correlation with big heads. Brodner W et al. 2004 [14] divided patients in 3 groups with different cup inclination, but found no difference in ion levels between the three groups in THA with $28 \mathrm{~mm}$ metal heads, except for 3 cases with very steep cups. It seems logical, that edge wearing in steep cups could result in higher ion levels, although we have not been able to demonstrate such a correlation in this study, maybe due to the narrow confidence limits for cup placement.

This study found no difference in head size between patients with or without groin pain and with or without elevated ion levels. Data from the Australian joint registry [15] did not show any difference in revision rate, with different head size in MoM THA, but an inverse relationship between femoral head size and risk of revision in RTHA. Langton et al. 2008 [13] showed higher ion levels with small heads in RTHA. S Glyn-Jones et al. 2009 [16] could not, in a large patient cohort with RTHA, show significant relation between small head and revision rate in RTHA. We have not found any literature on large head metal on metal THA, and

the effect of head size on pain and elevated ion levels. Larger

Table 2. Comparison of Statistics Between Cases with and without Self Reported Groin Pain

\begin{tabular}{|c|c|c|c|}
\hline & No Groin Pain N=246 (Mean) & Self Reported Groin Pain N=68 (Mean) & Value P \\
\hline \hline Age at operation $\S$ & 57 years (CI 95\%: 55.8-58.4) & 49.7 years (CI 95\%: 46.6-52.9) & $\mathrm{P}<.01$ \\
\hline Time to follow Up $\S$ & 3.3 years (CI 95\%: 3.1-3.5) & 3.5 years (CI 95\%: 3.2-3.9) & $\mathrm{P}=.22$ \\
\hline Femoral head $\S$ & $46 \mathrm{~mm}(\mathrm{CI} 95 \%: 45.3-46.7)$ & $45,5 \mathrm{~mm}(\mathrm{CI} 95 \%: 44.2-47)$ & $\mathrm{P}=.59$ \\
\hline Sex (M/F) $\dagger$ & $139 / 109$ & $34 / 34$ & $\mathrm{P}=.38$ \\
\hline Type of cup $\dagger$ & $58 \mathrm{M} 2 \mathrm{a} 38 / 190$ magnum & $18 \mathrm{M} 2 \mathrm{a} 38 / 50$ magnum & $\mathrm{P}=.60$ \\
\hline
\end{tabular}


Table 3. Comparison of Statistics in Cases with Normal and Increased Cobolt and Chromium Values in Whole Blood Samples

\begin{tabular}{|c|c|c|c|}
\hline & $\begin{array}{l}\text { Normal Chrome and Cobolt Levels } \\
(<7 \mathrm{ppm}) \mathrm{N}=\mathbf{3 5} \text { (Mean) }\end{array}$ & $\begin{array}{l}\text { Increased Chrome and Cobolt Levels } \\
(>7 \text { ppm) } N=15 \text { (Mean) }\end{array}$ & $\begin{array}{c}\text { Value } \\
(\mathbf{P}<0.05)\end{array}$ \\
\hline Age at operation $\S$ & $\begin{array}{c}53.5 \text { years } \\
\text { (CI } 95 \%: 49-57.9)\end{array}$ & $\begin{array}{c}55.3 \text { years } \\
\text { (CI 95\%: 47.2-63.4) }\end{array}$ & $\mathrm{P}=.66$ \\
\hline Time to Follow Up $\S$ & $\begin{array}{c}3.45 \text { years } \\
\text { (CI } 95 \%: 2.9-4)\end{array}$ & $\begin{array}{c}3.16 \text { years } \\
\text { (CI } 95 \%: 2.3-4)\end{array}$ & $\mathrm{P}=.53$ \\
\hline $\operatorname{Sex}(M / F) \dagger$ & $21 / 14$ & $4 / 11$ & $\mathrm{P}=.03$ \\
\hline Type of cup $\dagger$ & $10 \mathrm{M}_{2} \mathrm{~A} 38 / 25$ magnum & $5 \mathrm{M}_{2} \mathrm{~A} 38 / 10$ magnum & $\mathrm{P}=.73$ \\
\hline Satisfaction $(+/-) \dagger$ & $28 / 7$ & $10 / 5$ & $\mathrm{P}=.31$ \\
\hline Harris Hip Score (0-100 points) $\S$ & $\begin{array}{l}74 \text { points } \\
\text { (CI 95\%: 67.5-80.5) }\end{array}$ & $\begin{array}{l}68.8 \text { points } \\
\text { (CI } 95 \%: 55.6-82.2)\end{array}$ & $\mathrm{P}=.47$ \\
\hline
\end{tabular}

diameter heads lubricates better [17], which might be the reason why these heads results in lower ion levels, and less risk of revision with RTHA. In addition small head RTHA are also prone to higher risk of impingement, which might result in higher revision rate. It seems, that the data from RTHA studies, may not be truly reflective for MOM THA [18].

Significant higher ion levels were found in females. Haan et al. 2008 [12] likewise found significant higher ion levels in females in a large patient cohort of RTHA. Langton et al. 2008 [13] could not, in a small sample size, show this connection between gender and elevated ion levels with RTHA. Thus, female gender might be a risk factor for elevated ion levels. This could be explained by higher peak contact pressure in the hip joint in females, due to anatomical differences in the pelvis between male and female [19]. As head size was not found to be predictive for elevated ion levels, smaller head size with women could probably not explain this difference between the gender.

This study found one case with pseudotumor that probably can be ascribed to the MoM articulation and one case with a transient bursa iliopectineus that most likely cannot be ascribed to material of the articulation. In the case with pseudotumor we found grade 8 ALVAL reaction, a clinically loose cup and a large effusion. The patient insisted on operation on the opposite side too, where we found a well-fixed prosthesis, without any reactions and no signs of ALVAL on the histological specimens. One can speculate on these findings. Is it possible to have an allergic reaction in one hip and not the other similar hip, or are we facing a mechanical problem with initial fixation problems with monoblock metal cups?

The limitations with this multi-centre study are that different observers reviewed the patients. The patients were located through a register and registers are known to be false, in some instances, due to insufficient registration. There seems to be a high level of misinterpretation of the question, on groin pain, as $12 / 62$ patients with self reported groin pain, did not have groin pain on examination.
This study was performed with 1.1 to 6.4 years follow up. Onset of symptoms with RTHA is often within one year. In one publication mean time to image identification of the diagnosis of pseudotumor in RTHA has been reported to be 22 month, diagnostic delay however unknown [20]. Late onset symptoms up to 58 month are reported too [21]. No study has been found that reported the onset of symptoms in MOM THA. The relatively short minimum follow up period does potentially mean that the present study might have missed some late onset reverse reactions. As this investigation has not scanned all patients, there might be some non-symptomatic adverse reactions that have been missed. It does, however, seems reasonable to assume that non-symptomatic cases will become symptomatic if they continue to increase in size. The strength with this study is, that 2 clinics are involved and, the same author has performed all measurements on radiographs. In addition we have a large sample of patients, with only a few patients lost to follow up.

In conclusion the present study seem to have an incidence of adverse reaction far less than $1 \%$, which is in accordance with another study with this prosthesis [22]. For the moment the use of MoM articulation in Denmark has come to a halt due to bad publicity from the inferior results of a single brand of MoM prosthesis. Further follow up studies should reveal the true nature and frequency of the problems with pseudotumor and the relation to the MoM articulation. The most important issue at the moment seems to be to establish the aetiology of the problem and based on this aetiology to get a firm definition of a pseudotumor in order to be able to compare results from different studies.

\section{CONTRIBUTION OF AUTHORS}

Jens Stürup: Coordinating data collection, collection of data from Rigshospitalet and writing.

Line Borreskov Dahl: Coordinating data collection, collection of data from Rigshospitalet and writing.

Karl- Erik Jensen: Description of radiographic technique and evaluation of ct-scans and writing. 
Hospital

Anne Birgitte Larsen: Collection of data from Hvidovre

Peter Gebuhr: Coordinating and collection of data from Hvidovre Hospital and writing.

\section{ACKNOWLEDGEMENT}

Declared none.

\section{CONFLICT OF INTEREST}

The present study has been sponsored by Biomet inc. with a grant covering expenses for blood sample analysis and the salary for a part time nurse for collection of data.

\section{REFERENCES}

[1] Lombardi AV, Skeels MD, Adams JB. Do large heads enhance stability and restore native anatomy in primary total hip arthroplasty. Clin Orthop Relat Res 2011; 469: 1547-53.

[2] http://www.ortopaedi.dk/fileadmin/nyhedsbrev/nov2010/Final_MoM adhocudvalg 27-okt-2010.pdf

[3] Willert HG, Buchhorn GH, Fayyazi A, et al. Metal-on-Metal bearings and hypersensitivity in patients with artificial hip joints. $\mathrm{J}$ Bone Joint Surg 2005: 87A: 28-36.

[4] Campbell P, Ebramzadeh E, Nelson S, et al. Histological features of pseudotumor-like tissues from metal-on-metal hips. Clin Orthop Relat Res 2010; 468: 2321-7.

[5] Jensen P, Thyssen JP, Retpen JB, Menné T. Cobalt allergy and suspected aseptic lymphocyte-dominated vascular-associated lesion following total hip arthroplasty. Contact Dermatitis 2009; 61(4): 238-9.

[6] Carli A, Reuven A, Zukor D et al. Adverse soft-tissue reactions around non-metal-on-metal total hip arthroplasty. A systematic review of the literature. Bulletin of the NYU Hospital for Joint Diseases 2011; 69: S47-51

[7] Pandit H, Glyn-Jones S, Malardy-Smith P, et al. Pseudotumors associated with metal-on-metal hip resurfacings. J Bone Joint Surg Br. 2008; 90: 847-51.

[8] Kwon YM, Glyn-Jones S, Simpson DJ, et al. Analysis of wear of retrieved metal-on-metal hip resurfacing implants revised due to pseudotumors. J Bone Joint Surg Br 2010; 92B: 356-61.

[9] Smolders JMH, Bisseling P, Hol A, et al. Metal ion interpretation in resurfacing versus conventional hip arthroplasty and in whole blood versus serum. How should we interpret metal ion data. Hip Int 2011; 21(5): 587-95.

[10] Bartel RB, Yuan BJ, Trousdale RT, Sierra RJ. The prevalence of groin pain after metal-on-metal total hip arthroplasty and total hip resurfacing. Clin Orthop Relat Res 2010; 468: 2346-56.

[11] Nasser AB, Beaule PE, O'Neill M, Kim PR, Fazekas A. Incidence of groin pain after metal-on metal hip resurfacing. Clin Orthop Relat Res 2010; 468: 392-9.

[12] De Haan R, Pattyn C, Gill HS, et al. correlation between inclination of the acetabular combonent and metal ion levels in metal-on-metal hip resurfacing replacement. J Bone Joint Surg 2008; 90B: 1291-7.

[13] Langton DJ, Jameson SS, Joyce TJ, et al. The effect of component size and orientation on the concentration of metal ions after resurfacing arthroplasty of the hip. J Bone Joint Surg 2008; 90B: 1143-51.

[14] Brodner W, Grübl A, Jankovsky R, et al. Cup inclination and serum concentration of chrome and chromium after metal on metal total hip arthroplasty. J Arthroplasty 2004; 19: 66-70.

[15] Australian Orthopaedic Association National Joint Replacement Registry. Hip and knee arthroplasty Annual Report 2008. http: //www.dmac.adelaide.edu.au/aoanjrr/documents/aoanjrrreport_200 8.pdf (date last accessed 28 feb 2012).

[16] Glyn-Jones S, Pandit H, Kwon YM, et al. Risk factors for inflammatory pseudotumor formation following hip ersurfacing. J Bone Joint Surg 2009; 91B: 1566-75.

[17] Dowson D, Hardaker C, Flett M, et al. A hip joint simulator study of the performance of metal-on-metal joints. J Arthroplasty 2004; 19(8): 124-30.

[18] Malviya A, Ramaskandhan J, Holland JP, Lingard EA. Metal-onMetal total hip arthroplasty. J Bone Joint Surg 2010; 92A: 1675-83.

[19] Genda E, Iwasaki N, Li G, et al. Normal hip joint contact pressure distribution in single-leg standing-effect of gender and anatomic parameters. J Biomechanics 2001; 34: 895-905.

[20] Fang SJF, Harvie P, Gibbons CLMH, et al. The image spectrum of peri-articular inflammatory, asses following metal-on metal hip resurfacing. Skeletal Radiol 2008: 37; 715-22.

[21] Pandit H, Vlychou M, Whitwell D, et al. Necrotic granulomatous pseudotumors in bilateral resurfacing hip arthoplasties: evidence for a type IV immune response. Virchows Arch 2008; 453: 529-34.

[22] Meding JB, Meding KJ, Keating EM, et al. Low incidence of groin pain and early failure with large metal articulation total hip arthroplasty. Clin Orthop Relat Res 2011; 470: 388-94. 